\title{
O ENSINO MUSICAL NA EDUCAÇÃO INFANTIL E SUA POSSÍVEL RELAÇÃO COM A TEORIA DESENVOLVIMENTAL PROPOSTA POR L. VIGOTSKI
}

\section{MUSICAL TEACHING IN CHILDHOOD EDUCATION AND ITS POSSIBLE RELATIONSHIP WITH THE DEVELOPMENTAL THEORY PROPOSED BY L. VIGOTSKI}

\author{
Cícero Rodarte Mião \\ Universidade Estadual Paulista "Júlio de Mesquita Filho" \\ cicerorodarte@gmail.com \\ Sonia Regina Albano de Lima \\ Universidade Estadual Paulista "Júlio de Mesquita Filho" \\ soniaalbano@uol.com.br
}

\section{Resumo}

texto a seguir pontua a importância do ensino musical durante a Educação Infantil propagada nos ordenamentos pedagógicos voltados para essa faixa etária, mais intensamente esboçado na Base Nacional Comum Curricular (BRASIL, 2018). Também se preocupou em apontar como a Teoria Desenvolvimental de Vigotski pode fundamentar parte das ações, práticas e atividades ali presentes, subsidiando uma proposta de ensino artístico que toma para si aspectos voltados para a valorização histórico social deste ensino. A partir desse relato fica notório a necessidade de implantarmos um ensino musical que se estenderá desde a fase infantil até a educação básica.

Palavras-chave: ensino musical; teoria desenvolvimental de Vigotski; valorização das artes para o desenvolvimento humano integral; o ensino musical enquanto processo histórico-social. 


\begin{abstract}
The following text points out the importance of musical education during Early Childhood Education propagated in the pedagogical ordering geared towards this age group, more intensely outlined in the National Common Curricular Base (BRASIL, 2018). He was also concerned with pointing out how Vigotski's Developmental Theory can substantiate part of the actions, practices and activities present there, subsidizing an artistic teaching proposal that takes aspects towards the social and historical valorization of this teaching. From this report, the need to implement a musical education that extends from childhood to basic education becomes clear.
\end{abstract}

Keywords: musical education; Vygotsky's developmental theory; valuing the arts for integral human development; musical education as a historical-social process.

\title{
A BNCC ENQUANTO DOCUMENTO PEDAGÓGICO VOLTADO PARA A EDUCAÇÃO INFANTIL E EDUCAÇÃO BÁSICA
}

Este artigo tem como objetivo primeiro demonstrar a importância do ensino musical para o desenvolvimento integral de crianças, seja ele psíquico, corporal, cognitivo, estético ou sociológico. Para fundamentarmos nossa proposta recorrermos aos textos de Lev Vigotski', que abordam os conceitos de Zona de Desenvolvimento Iminente, Catarse e a Imitação (VICOTSKI, 2009).

Sem a pretensão de realizarmos uma análise crítica da Base Nacional Comum Curricular para a educação infantil (BRASIL, BNCC, 2018), este ordenamento será contemplado em nosso texto por se tratar de um documento de caráter normativo que define o conjunto orgânico

I Optou-se por utilizar a transliteração do nome Lev Vygotsky como L. Vigotski, por ser essa a forma utilizada na obra base que fundamentou nosso texto, a saber, "A construção do pensamento e linguagem" - versão integral do texto original - traduzido diretamente do russo por Paulo Bezerra. Porém, sabemos que a forma mais utilizada na escrita do nome desse autor é Vygotsky, devido às traduções feitas do inglês para o português. Vale apontar que as versões em língua inglesa foram as que sofreram maiores cortes, além de serem as primeiras que chegaram ao Brasil com maior disseminação. In: PRESTES, 2010, p. 90. 
e progressivo de aprendizagens essenciais que todos os alunos devem desenvolver ao longo das etapas e modalidades da educação básica, de modo que tenham assegurados seus direitos de aprendizagem e desenvolvimento de conformidade com o que preceitua o Plano Nacional de Educação (PNE) que determina diretrizes, metas e estratégias para a política educacional no Brasil, no período de 2014 a 2024.

$\bigcirc$ PNE foi aprovado pela Lei n. 13.005/14, artigo $1^{\circ}$, quando definiu as 10 diretrizes que devem guiar a educação brasileira e estabeleceu 20 metas a serem cumpridas em sua vigência, que não serão aqui relatadas por fugirem um pouco do nosso foco de análise. Essa mesma lei reitera o princípio de cooperação federativa da política educacional, já presente na Constituição Federal e na Lei de Diretrizes e Bases da Educação Nacional, ao estabelecer que a União, os Estados, o Distrito Federal e os Municípios atuarão em regime de colaboração, visando ao alcance das metas e à implementação das estratégias objeto pelo Plano, cabendo aos gestores federais, estaduais, municipais e do Distrito Federal a adoção das medidas governamentais necessárias ao alcance das metas previstas no documento (BRASIL, Lei ก. $13.0005 / 14$, art. $\left.1^{\circ}\right)^{2}$.

Dito isso, não iremos estabelecer uma relação direta das ideias de L Vigotski com a BNCC, mas verificarmos como este documento trata a educação infantil para posteriormente verificarmos o quanto a teoria desenvolvimental de Vigotski, de forma subjetiva, pode estar presente em algumas ideias presentes neste ordenamento.

Conforme expresso, a Base Nacional Comum Curricular visa a formação humana integral e a construção de uma sociedade justa, democrática e inclusiva e para que essa proposta se realize, estabelece 10 (dez) competências que consubstanciam, no âmbito pedagógico, os direitos de aprendizagem e desenvolvimento e se aplicam para as três etapas da Educação Básica (educação infantil, ensino fundamental e ensino médio) (BRASIL, BNCC, INTRODUÇÃO, 2018). Duas dessas competências são destinadas diretamente ao ensino das artes e são elas que diretamente nos interessa:

2 Acesso em 19 de dezembro de 2020 - http://pne.mec.gov.br/ instancia-permanente-de-negociacao-e-cooperacao\#footer.

\section{6}

REV. TULHA, RIBEIRÃO PRETO, v. 6, n. 2, pp. 64-89, jul.-dez. 2020 
Valorizar e fruir as diversas manifestações artísticas e culturais, das locais às mundiais, e também participar de práticas diversificadas da produção artístico-cultural. Utilizar diferentes linguagens - verbal (oral ou visualmotora, como Libras, e escrita), corporal, visual, sonora e digital -, bem como conhecimentos das linguagens artística, matemática e científica, para se expressar e partilhar informações, experiências, ideias e sentimentos em diferentes contextos e produzir sentidos que levem ao entendimento mútuo (BRASIL, BNCC, INTRODUÇÃO, 2018).

No que se reporta a Educação Infantil, tema central do nosso artigo, há que se considerar que após a promulgação da LDB $n^{10}$ 9394/96, a Educação Infantil passa a ser parte integrante da Educação Básica, situando-se no mesmo patamar do Ensino Fundamental e do Ensino Médio. Com a antecipação de acesso ao ensino fundamental para crianças a partir dos 4 (quatro) anos de idade, em decorrência da Emenda Constitucional n. 59/093, a educação infantil nas creches e pré-escolas passou a atender crianças na faixa etária de (0) zero a (5) cinco anos e onze meses. As creches abrigariam bebês de (O) zero a (1) um ano e (6) seis meses, e crianças de (1) um ano e (7) sete meses a (3) três anos e ( 11 ) onze meses; já a pré-escola abrigaria crianças pequenas de (4) quatro anos a (5) cinco anos e (11) onze meses.

$\bigcirc$ ensino infantil ali propagado, teve como objetivo garantir os direitos de aprendizagem e desenvolvimento da criança, considerados essenciais para sua formação integral. Nesse sentido foram instituídos os seguintes direitos de aprendizagem e desenvolvimento para a educação infantil: o conviver, o brincar, o participar, o explorar, o se expressar e o se conhecer. Para atender esses direitos a BNCC estabeleceu 5 (cinco) campos de experiência: 1 - o eu, o outro e o nós; 2- corpo, gestos e movimentos; 3-traços, sons, cores e formas; 4- escuta, fala, pensamento e imaginação; 5- espaços, tempos, quantidades, relações e transformações, que se destinam aos três grupos etários acima relatados (BRASIL, BNCC, 2018, pp. 40-43).

Nesse contexto, foi instituido no ordenamento que as creches e pré-escolas, ao acolher as vivências e os conhecimentos construídos pelas crianças no ambiente da família e no contexto de sua comunidade,

3 A Emenda Constitucional n. 59/09 estendeu a obrigatoriedade do ensino gratuito para criança de 4 anos. 
e articulá-los em suas propostas pedagógicas, têm o objetivo de ampliar o universo de experiências, conhecimentos e habilidades dessas crianças, diversificando e consolidando novas aprendizagens, atuando de maneira complementar à educação familiar, especialmente quando se tratar da educação dos bebês e das crianças bem pequenas, que envolve aprendizagens muito próximas aos dois contextos (familiar e escolar), como a socialização, a autonomia e a comunicação. Conforme expresso no ordenamento, nessa direção, e para potencializar as aprendizagens e o desenvolvimento das crianças, a prática do diálogo e o compartilhamento de responsabilidades entre a instituição de Educação Infantil e a familia são essenciais. Além disso, a instituição precisa conhecer e trabalhar com as culturas plurais, dialogando com a riqueza/diversidade cultural das familias e da comunidade (BRASIL, BNCC, 2018, p. 37).

Portanto, a redação articulada neste ordenamento, tenta promover um diálogo profundo entre a familia deste público infantil e a escola, o que segundo o relatado, poderá garantir o processo desenvolvimental da criança por meio de atividades pautadas na ludicidade, desafios e brincadeiras que possibilitarão o desenvolvimento, a aprendizagem e a socialização da criança (BRASIL, BNCC, 2018 ).

Nesse sentido, busca-se uma experiência significativa neste aprendizado, um contexto que possibilite a criança relacionar o que ela aprende com a sua vida e o seu cotidiano. Na BNCC a construção do significado de si, do outro e do mundo, deve ocorrer na criança de forma natural, tornando-se um componente potencializador não só para a resolução de seus problemas como também dos objetivos socioculturais a serem conquistados.

Sob essa ótica, a BNCC busca orientar instituições e educadores a estruturar um processo de experiências que favoreça todas as questões fundamentais para um desenvolvimento infantil que dialogue com o contexto no qual a criança está inserida. Conforme expresso: "parte do trabalho do educador é refletir, selecionar, organizar, planejar, mediar e monitorar o conjunto das práticas e interações, garantindo a pluralidade de situações que promovam o desenvolvimento pleno das crianças" (BRASIL, BNCC, 2018 , p. 39).

É importante apontar que o documento não traz atividades e ações prontas, bulas a serem adotadas, isso fica a cargo da escola. Ele 
também não trata de conteúdos específicos para a Educação Infantil, ele aponta campos de experiências que o educando deve vivenciar ao longo deste período. Essa estrutura, ao mesmo tempo que apresenta afirmações genéricas, por outro lado possibilita que a escola desenvolva sua prática pedagógica de maneira autônoma, aproximando-se mais da demanda social na qual ela está inserida. Isso se mostra um fator favorável para a implementação da educação musical como uma ação ativa e regular na Educação Infantil, bastante exemplificada nos textos da coletânea intitulada Ensino Musical Brasileiro: Múltiplos olhares (LIMA, 2020).

Assim exposto, justificam-se os estudos que buscam compreender e relacionar a música no desenvolvimento infantil, diante das possibilidades que a BNCC oferece. Nesse sentido, entendemos que a arte e mais especificamente - a música, manifesta-se como um fenômeno histórico cultural inerente ao desenvolvimento humano.

Com os cinco campos de experiência elencados, a BNCC busca dialogar com o cotidiano da criança sob uma perspectiva sociológica. intuito é formar um cidadão com as habilidades necessárias para conhecer a si mesmo e interagir com o meio. As organizações que os campos de experiência promovem, são consideradas fundamentais no processo devenvolvimental, na estruturação da psiquê, na criação de significados e na base cognitiva na qual se assenta a conceitualização espontânea e científica.

Os campos de experiência apontados no documento possuem características e objetivos próprios para a educação infantil e podem encontrar embasamento teórico nas ideias veiculadas por L. Vigotski.

\section{A IMPORTÂNCIA DA ARTE E DO ENSINO DAS ARTES SEGUNDO RELATOS DE L. VIGOTSKI}

É pertinente relatarmos a importância que Vigotski atribuiu ao ensino da Arte como meio de organização e desenvolvimento da psiquê humana. A Arte para ele, é um produto histórico-social, uma espécie de sentimento social prolongado ou uma técnica social de sentimentos, na qual o homem organiza seu mundo psíquico: 
[a] arte é o social em nós e, se o seu efeito se processa em um indivíduo isolado, isso não significa, de maneira nenhuma, que as suas raízes e a sua essência sejam individuais. É muito ingênuo interpretar o social apenas como coletivo, como existência da multiplicidade de pessoas. $\bigcirc$ social existe até onde há apenas um homem e as suas emoções pessoais (VICOTSKI, 200 I, p. 315 ).

- sentido da Arte e da educação estética para este autor manifesta-se no homem, do social para o individual, do externo para o interno, do externo/social para o interno/individual; por isso, o efeito da Arte nos indivíduos é sempre um efeito social. A relação que o homem estabelece com a Arte é um tanto complexa. Com ela os homens podem reconstruir a vida e trazer para o mundo um enfoque mais emocional e dialético:

Tudo consiste em que a arte sistematiza um campo inteiramente específico do psiquismo do homem social precisamente o campo do seu sentimento. E, embora todos os campos do psiquismo tenham como subjacentes as mesmas causas que o geraram, operando, porém, através de diversos Verhaltensweisen psíquicos, acabam dando vida a diversas formas ideológicas (VICOTSKI, 2001 , p. 12).

A Arte para este autor tem a função de equilibrar o universo interior do homem - uma necessidade imprescindivel para o seu psiquismo, o que contradiz veementemente a concepção de que ela é apenas um ornamento na vida social do indivíduo (VICOTSKI, 2001 , pp. 328-9).

prazer dos sentidos que a Arte pode gerar é motivo suficiente para que ela seja integrada ao currículo escolar. Ela não se configura tão somente como uma vivência estética; ela se perpetua como uma experiência cognitiva e emotiva intensa, que Vigotski chama de Catarse: "[...] as emoções angustiantes e desagradáveis são submetidas a certa descarga, à sua destruição e transformação em contrários, e de que a reação estética como tal se reduz, no fundo, a essa catarse, ou seja, à complexa transformação dos sentimentos" (VICOTSKI, 2001, p. 112). 
Esse sentimento profundo, teria um efeito transformador e purificador no psiquismo e, consequentemente, transformador dos sentimentos e pensamentos dos indivíduos.

Vigotski (2001) admite que a verdadeira experiência estética de fruição da arte - a Catarse Estética - promove uma vivência integral no homem, uma vivência que inclui a transformação das emoções, sentimentos e pensamentos, cuja elaboração intelectual, cognitiva e afetiva conduz a criações da imaginação e da fantasia. Esse seria, então, o aspecto peculiar da Arte - uma técnica social do sentimento, que tem o poder de transformar e purificar positivamente o psiquismo humano por meio de uma experiência integradora das emoções com o intelecto, do afeto com a cognição, do homem com o meio.

Sob o ponto de vista biológico, Vigotski acredita que a Catarse Estética seria capaz de promover as descargas de energia psicofísica necessárias para manter o equilibrio do psiquismo, uma vez que o homem teria muito mais possibilidades de vida do que aquelas que ele realmente consegue realizar em seu cotidiano. Dessa forma, o ser humano precisa da arte:

Dessa analogia, esboça-se o mecanismo dos processos psicológicos correspondentes à obra de arte, e ainda se estabelece que o caráter de símbolo ou imagem da palavra equipara-se à sua poeticidade e, deste modo, - fundamento da emoção artística passa a ter caráter de imagem, cuja natureza geral é constituída pelas propriedades comuns do processo intelectual cognitivo (VICOTSKI, 2001, p. 34, negrito nosso).

Vigotski considera a vivência artística um meio de o homem se transformar positivamente, de transcender a si mesmo, reorganizar sua estrutura psicológica e ressignificar o seu contexto em um processo dialético. Para ele a fruição artística é um ato criador, uma vez que exige do psiquismo humano um alto grau de elaboração emocional e cognitiva:

Eis por que a percepção da arte também exige criação, porque para essa percepção não basta simplesmente vivenciar com sinceridade o sentimento que dominou 0 
autor, não basta entender da estrutura da própria obra: é necessário ainda superar criativamente o seu próprio sentimento, encontrar a sua catarse, e só então o efeito da arte se manifesta em sua plenitude (VICOTSKI, 200 I, p. 314).

Por considerar a emoção artística imprescindivel para o psiquismo humano, além de fonte de desenvolvimento afetivo, emocional, cognitivo, social, dentre outros, Vigotski (2001) acredita que as artes devem integrar a educação regular, a fim de que o indivíduo possa desenvolver e manifestar atos criativos. Conforme ele expressa: "[...] qualquer ato artístico incorpora forçosamente, como condição obrigatória, os atos de conhecimento racional precedentes, as concepções, identificações, associações, etc" (VICOTSKI, 200 l, p. 325). Nessa perspectiva, ele ainda destaca que:

Para formular integralmente o ponto de vista dessa teoria sobre o procedimento de compreensão artística, cabe indicar que toda obra de arte, desse ponto de vista, pode ser aplicada como predicado à fenômenos novos ainda não aplicados ou ideias para aperceber-se deles, da mesma forma que a imagem na palavra ajuda que nos percebamos do novo significado. $\bigcirc$ que não estamos em condição de compreender diretamente, podemos compreender por via indireta, através da alegoria, e toda ação psicológica da obra de arte pode ser integralmente resumida ao aspecto indireto dessa via (VICOTSKI,200 I, p. 35).

Assim pensado, caberia à educação de modo geral, oferecer subsídios para que seus alunos pudessem ampliar suas possibilidades de experiência estética para além das fronteiras do cotidiano, sem negligenciá-las, pois, essa é a base para toda a estrutura psicológica desenvolvimental. 


\section{A TEORIA DESENVOLVIMENTAL HISTÓRICO-SOCIAL DE L. VIGOTSKI E O ENSINO INFANTIL}

O contexto histórico no qual Vigotski concebe a sua obra, transita complexamente entre situações políticas, econômicas, ideológicas e culturais, que colocam em evidência a própria perspectiva de psicologia em um âmbito de pesquisa. Contemporâneos do autor, na tentativa de aproximar a psicologia das ciências naturais, buscaram a objetividade concreta em suas observações, isso aproximou a perspectiva de desenvolvimento infantil naquilo que a criança consegue realizar (VICOTSKI, 2009). Em Vigotski, a subjetividade é levada em consideração e o materialismo da atividade é visto como processo, um contexto propício ao desenvolvimento que acontece dialeticamente, em relações que podem ser multiplamente construidas:

A análise atomística e funcional, que dominou na psicologia científica durante todo último decênio, redundou no seguinte: funções psicológicas particulares foram objetos de análise isolada; o método de conhecimento psicológico foi elaborado e aperfeiçoado para o estudo desses processos isolados e particularizados; ao mesmo tempo, a relação interfuncional e sua organização numa estrutura integral da consciência permaneceu sempre fora do campo da atenção dos pesquisadores. Para a psicologia moderna, não é nenhuma novidade que a consciência é um todo único e que funções particulares estão inter-relacionadas em sua atividade. Mas a unidade da consciência e os vínculos entre certas funções foram antes postulados pela psicologia que tornados objetos de pesquisa. Ademais, ao postular essa unidade funcional da consciência, a psicologia partia em todas suas investigações, do postulado falso, não formulado e tacitamente aceito por todos que reconheciam a imutabilidade e a permanência das relações interfuncionais e imaginava a percepção ligada sempre de uma mesma forma a atenção, assim como a memória estava ligada a percepção e o pensamento a memória. Daí a conclusão natural de que as relações interfuncionais são uma coisa que podem ser colocadas entre parênteses como multiplicidade genérica e ser desprezadas nas operações investigatória com as funções particulares isoladas entre parênteses (VICOTSKI, 2009, pp. 1-2). 
Os estudos de Vigotski (2009), pautados no materialismo dialético, veem o psiquismo humano e seu desenvolvimento como fruto de um processo histórico-social, ou seja, a matéria está em relação dialética com o psicológico e o social. Sua perspectiva de educação leva em consideração todo e qualquer processo que lance luz ao desenvolvimento, independente se o objetivo da atividade foi atingido ou não.

Vigotski ${ }^{4}$ compreende o ser humano como um ser histórico. Sua natureza se forma a partir da apropriação do universo sociocultural acumulado pela sua espécie. Não há como o homem se tornar um ser humano se não estiver inserido no cotidiano de sua sociedade, pois o que the confere "humanidade" ou "essência humana" é a capacidade de se apropriar da bagagem sociocultural acumulada historicamente pela humanidade. Essa é uma capacidade que os outros primatas não têm, eles não reconhecem sua história e não se apropriam dos conhecimentos acumulados pela experiência das gerações anteriores, uma vez que isso se dá pela fala complexamente estruturada, pela instrução, memória sequencial lógica, organizações estruturais psicológicas que possibilitam abstração e conceitualização, faculdades que dentre outras, são definidas pelo autor como Funções Superiores (VICOTSKI, 2009).

Para ele, o desenvolvimento das Funções Superiores começa a amadurecer de forma mais significativa com a intensificação da relação entre pensamento e a fala, por volta dos dois anos de idade. Essa relação se torna base para a estruturação da gênese psicológica e a relação com o mundo externo; nela "a fala se torna intelectual e o pensamento se torna verbal (VICOTSKI, 2009, p. 132). As possibilidades de significado que essa fase desenvolvimental possibilita, parte de associações concretas que a percepção da criança possibilita do abstrato que as organizações conceituais lançam luz. Assim, elementos como a imitação no processo de aprendizagem, são estabelecidos como uma via que favorece esse direcionamento desenvolvimental.

4 Pautados nessas questões discutidas, partimos da perspectiva que o autor apresenta na obra "A construção do pensamento e da linguagem", publicado pela editora Martins Fontes, traduzido por Paulo Bezerra, edição de 2009. Essa obra, além de tratar diretamente do desenvolvimento infantil, apresenta a tradução do texto original - russo -, na integra - último escrito de Vigostki datado em 1934, dois anos antes de sua morte prematura (In: PRESTES, 2010). 
Para Vigotski (2009) o processo de desenvolvimento e aprendizagem da criança tem como uma de suas bases, o procedimento de imitação e a apropriação das objetivações cotidianas, fundamentais para o desenvolvimento cognitivo e para a formação integral do homem. Nesse caso, tanto a imitação como a apropriação acontecem espontaneamente no processo de desenvolvimento do psiquismo infantil, pelo simples fato de a criança estar inserida no cotidiano de sua sociedade, o que possibilita a mediação cultural. Toda criança está constantemente aprendendo desde o momento em que nasce e até mesmo, antes disso. A imitação possibilita que ela crie novos significados, reestabeleça outros e estruture novas associações.

Para Vigotski $(2005,2009)$ todo e qualquer processo de imitação deve ter significado para a criança, ou seja, ela não imita o que não faz sentido para ela. A percepção e a estruturação desses signos parte das organizações psicológicas da criança e é uma forma de ela vivenciar o mundo exterior em diálogo com o sev eu interior e suas subjetividades. Por outro lado, esse processo também é a própria recriação constante da subjetividade.

aprendizado formal não acontece a partir do "nada", ou seja, não se inicia da "estaca zero", mas está assentado sobre o conhecimento cotidiano pré-escolar da criança (VICOTSKI 2005, p. 8-9), o que nos dias atuais corresponde à faixa etária da educação infantil. Esse conhecimento é adquirido por meio da apropriação das objetivações socioculturais da vida cotidiana e sofre relevantes alterações quando a criança adentra na escola regular e no sistema de ensino (VICOTSKI, 2009).

Não se trata de negar o conhecimento cotidiano e muito menos de considerá-lo inferior ao conhecimento formal, mas sim, considerálo a base psicológica para novas abstrações e aprendizados. $\bigcirc$ conhecimento formal em Vigotski, não diz respeito necessariamente à metodologia pedagógica utilizada nessa aprendizagem, mas sim à natureza do que se aprende e sua relação com o dia a dia.

Se é verdade que o pensamento da criança é ainda mais original do que a sua linguagem (e essa tese de Piaget nos parece indiscutivel), então devemos admitir necessariamente que as formas mais elevadas de pensamento, inerentes à formação dos conceitos científicos 
devem distinguir-se por uma originalidade ainda maior em comparação com aquelas formas de pensamento que participam da organização dos conceitos espontâneos, e que tudo que Piaget disse a respeito dessas últimas também devem ser aplicados aos conceitos científicos. É difícil admitir a ideia de que a criança assimilou, mas não reelaborou a seu modo os conceitos científicos, que estes the chegaram imediatamente aos lábios da forma mais tranquila. Tudo consiste em entender que a formação dos conceitos científicos, na mesma medida que os espontâneos, não termina, mas apenas começa no momento em que a criança assimila pela primeira vez um significado ou termo novo para ela, que é veículo de conceito científico. Essa é a lei geral do desenvolvimento do significado das palavras, à qual estão igualmente subordinados em seu desenvolvimento, tanto os conceitos científicos quanto os espontâneos (VICOTSKI, 2009, p. 265).

Vigotski, ao discutir o processo de aprendizagem, estabelece um conceito amplamente difundido na produção científica em educação no Brasil, a "Zona de Desenvolvimento Iminente"5 (ZDI). Nele, a aprendizagem pauta-se no conhecimento das potencialidades da criança. A aprendizagem e o desenvolvimento são processos que se diferem na concepção de Vigotski (2005, pp. 15-7). Se a criança aprende algo, não quer dizer que ela não continuará o seu processo desenvolvimental, por outro lado, se ela não consegue realizar uma tarefa, não quer dizer que não há um desenvolvimento acontecendo. Contudo, apesar de serem faculdades diferentes, a aprendizagem impulsiona e é fonte determinante do desenvolvimento. Portanto, ambos, aprendizagem e desenvolvimento são processos em íntima relação dinâmica, complexa e dialética.

Vigotski (2005, 2009) relata que o desenvolvimento infantil se manifesta em dois níveis: Desenvolvimento Independente (das ações que a criança pode realizar por si mesma) e o Desenvolvimento Potencial (que compreende as capacidades de agir que a criança tem em potencial, com a ajuda de outra pessoa). O Desenvolvimento Potencial

5 Devido aos desafios de tradução em um processo histórico no qual a obra de Vigotski passou por diversas censuras e cortes, além do fato de que as traduções em português vieram, em sua maioria, de outras línguas, e não do russo - idioma original da obra optamos utilizar, pautado em Prestes (2010) o termo Iminente ao invés do termo Proximal, que é o mais difundido, porém mais distante do sentido focado pelo autor (negrito nosso). 
apresenta características de um nível desenvolvimental que a criança ainda não estabeleceu por completo, um nível a seguir, que virá, mais cedo ou mais tarde, ou seja, um nivel iminente. Esse terreno entre o desenvolvimento independente e o que virá a seguir é a Zona de Desenvolvimento Iminente.

Portanto, a criança ao imitar as ações e operações de outros, traz em si uma estrutura que the possibilita estabelecer um significado para realizar tais tarefas. Assim, a imitação é um procedimento que também age na ZDI, ou seja, na capacidade potencial de aprendizagem. Segundo Vigotski (2005, p. 12) a criança pode imitar um grande número de ações - senão um número ilimitado - que supera os limites da sua capacidade atual. Com o auxílio da imitação na atividade coletiva guiada por pares, a criança pode fazer muito mais do que consegue com a sua capacidade de compreensão de modo independente. A diferença entre o nivel das tarefas realizáveis com o auxilio de terceiros e o nivel das tarefas que podem se desenvolver com uma atividade independente, define, por tanto, a área de desenvolvimento iminente e potencial da criança.

Para favorecer o desenvolvimento das crianças, a situação deve oferecer conhecimentos que ultrapassam seu nivel de desenvolvimento efetivo, tarefas que introduzem o novo e os desafios a serem vencidos. Nesse sentido, Vigotski relata:

Um ensino orientado até uma etapa do desenvolvimento já realizado é ineficaz sob o ponto de vista do desenvolvimento geral da criança, não é capaz de dirigir o processo de desenvolvimento potencial, mas vai atrás dele. A teoria do âmbito do desenvolvimento potencial origina uma fórmula que contradiz exatamente a orientação tradicional: o único bom ensino é o que se adianta ao desenvolvimento (VICOTSKI, 2005, p. 14).

Para agir no nível de desenvolvimento potencial da criança e impulsionar seu desenvolvimento, todo ensino/aprendizagem deve oferecer algo "a mais", algo que a desafie.

Se nos reportamos ao ensino musical, esse algo "a mais" poderia ser a descoberta de novas possibilidades, dentro de um espectro que 
seja significativo ao educando. $\bigcirc$ novo implica em reorganizações de significados já existentes, reestruturação conceitual, psicológica e afetiva (VICOTSKI, 2009). Isso não se limita de modo algum ao refinamento de habilidades. Podemos perceber um exemplo disso na ampliação do repertório do educando. Nesse sentido, é possivel observar o desenvolvimento sobre o elemento sonoro tornar-se independente e lançar voo a novos significados, em profundo diálogo com todo o processo desenvolvimental humano.

Assim relatado, seguimos nosso artigo buscando verificar em que medida o ensino musical na educação infantil pode dialogar com o desenvolvimento humano em uma perspectiva vigotskiana, e de que forma isso se relaciona com as propostas apresentadas nas normas instituídas pela BNCC, enquanto documento norteador da educação infantil.

\section{O DESENVOLVIMENTO INFANTIL E O ENSINO MUSICAL NA EDUCAÇÃO INFANTIL}

Nesse item pretendemos avaliar três aspectos básicos que devem ser discutidos e avaliados no presente texto. $\bigcirc$ primeiro deles é considerar a música como uma área de conhecimento necessária ao desenvolvimento integral da criança. A segunda é pensar na importância que L. Vigotski atribuiu as Artes e ao Ensino Artístico para o desenvolvimento humano. O terceiro aspecto é avaliar em que medida as ideias propagadas pela BNCC corroboram com a implementação da educação musical na Educação Infantil.

Avaliados esses três aspectos fica evidenciada a importância do ensino musical na fase infantil. $\bigcirc$ primeiro campo de experiência que a BNCC apresenta para o ensino infantil é "O eu, o outro o outro e nós". Nas características gerais desse campo, objetiva-se contemplar a relação da criança com o meio e com o outro, na construção das subjetividades, o que possibilitará para a criança a consciência individual e social, como critério de respeito à diversidade cultural, a identidade e aos diferentes tipos de costumes (BRASIL, BNCC, 2018, p. 40, negrito nosso). 
Nesse item, é enfatizado a relação com pares e com o contexto. Além disso, a interação comunicativa também está presente, como objetivo, em todas as faixas etárias da educação infantil (BRASIL, BNCC, 2018). Essas habilidades são inerentes ao ser humano em uma perspectiva sociocultural. Esse contexto contribui para a estruturação da fala, bem como sua relação com o pensamento em diferentes níveis, desse de sua gênese até o pensamento conceitual (VICOTSKI, 2009). As estruturas base da fala, sua relação com o pensamento, e a aplicação disso a um contexto com pares, podem possibilitar um ambiente rico e propicio ao estabelecimento das bases psicológicas necessárias para um desenvolvimento das potencialidades da criança, como apresentado em Vigotski em seus mais diversos âmbitos.

O próximo campo da BNCC é o “Corpo, gestos e movimentos", essa experiência comtempla áreas do desenvolvimento que correspondem, além da conscientização corporal, a espacialidade e temporalidade. A associações e estruturações se dão por meio da ação, do gesto, da linguagem e da inter-relação com pares e com o ambiente. Nesse item, a música aparece, primeiramente em suas características gerais:

Por meio das diferentes linguagens, como a música, a dança, o teatro, as brincadeiras de faz de conta, elas (as crianças) se comunicam e se expressam no entrelaçamento entre corpo, emoção e linguagem. As crianças conhecem e reconhecem as sensações e funções de seu corpo e, com seus gestos e movimentos, identificam suas potencialidades e seus limites, desenvolvendo, ao mesmo tempo, a consciência sobre o que é seguro e o que pode ser um risco à sua integridade física (BRASIL, BNCC, 2018, p. 41, negrito nosso).

A música na BNCC é reconhecida como uma linguagem que carrega suas essências simbólicas e significativas que são aquelas da sociedade que a produz. Portanto, essa arte é material e área de conhecimento, que quando apropriada em um processo histórico de instrução e representações acumulativas, torna-se inerente ao processo desenvolvimental humano, tal como descrito anteriormente nesse texto. Outo ponto a ser notado, é que a BNCC, neste campo de experiência, também está em concordância com o que trouxemos de Vigotski (200 l): "Movimentar as partes do corpo para exprimir corporalmente emoções, necessidades e desejos", direcionados a bebês de (0) zero a (18) 
dezoito meses e "Criar com o corpo formas diversificadas de expressão de sentimentos, sensações e emoções, tanto nas situações do cotidiano quanto em brincadeiras, dança, teatro, música" voltados para crianças entre (4) quatro anos e (5) cinco anos e ( 1 l) onze meses (BRASIL, BNCC, 2018 , p. 47). Esses elementos, além da música, enfatizam outras áreas da Arte como a dança e as artes cênicas. Nesse sentido, as artes - teatro, dança, artes visuais e música - são contempladas na BNCC, em uma direção única, que é a formação integral da criança.

Outro aspecto que a BNCC apresenta com relevância nos objetivos desse campo de experiência, é a imitação. Para bebês até (18) dezoito meses, o documento tem como intuito "Imitar gestos e movimentos de outras crianças, adultos e animais", ou mesmo "Apropriarse de gestos e movimentos de sua cultura no cuidado de si e nos jogos e brincadeiras" com as crianças entre (1) um ano e (7) sete meses e (3) três anos e ( 11 ) onze meses, ou até "Criar movimentos, gestos, olhares e mímicas em brincadeiras, jogos e atividades artísticas como dança, teatro e música" para crianças dos anos finais da educação infantil (BRASIL, BNCC, 2018, p. 47). Essa última questão, além de ir de encontro à imitação pela mímica, revela a Arte como via para esse processo, seja no âmbito da expressão imitativa ou mesmo da criação.

O seguinte campo de experiência é o que corresponde aos Traços, sons, cores e formas (negrito nosso). Esse campo contempla, praticamente, todas as concepções de Vigotsky expostas neste texto. $\bigcirc$ desenvolvimento com base nas significações espontâneas, o envolvimento integral do ser no processo de Catarse, a ZDI em todas a suas possiblidades, principalmente no que diz respeito ao processo de imitação, tão presente no fazer musical, além das questões sócio históricas que fundamentam as bases sociais e individuais do ser humano. Vejamos o que o ordenamento expressa nesse campo de experiência:

Conviver com diferentes manifestações artísticas, culturais e científicas, locais e universais, no cotidiano da instituição escolar, possibilita às crianças, por meio de experiências diversificadas, vivenciar diversas formas de expressão e linguagens, como as artes visuais (pintura, modelagem, colagem, fotografia etc.), a música, o teatro, a dança e o audiovisual, entre outras. Com base nessas experiências, elas se expressam por várias linguagens, criando suas próprias produções artísticas ou culturais, exercitando a 
autoria (coletiva e individual) com sons, traços, gestos, danças, mímicas, encenações, canções, desenhos, modelagens, manipulação de diversos materiais e de recursos tecnológicos. Essas experiências contribuem para que, desde muito pequenas, as crianças desenvolvam senso estético e crítico, o conhecimento de si mesmas, dos outros e da realidade que as cerca. Portanto, a Educação Infantil precisa promover a participação das crianças em tempos e espaços para a produção, manifestação e apreciação artística, de modo a favorecer o desenvolvimento da sensibilidade, da criatividade e da expressão pessoal das crianças, permitindo que se apropriem e reconfigurem, permanentemente, a cultura e potencializem suas singularidades, ao ampliar repertórios e interpretar suas experiências e vivências artísticas (BRASIL, BNCC, 2018, p. $41)$.

A importância das linguagens artísticas, que se estende também para a música, é evidentemente relevante para o processo de desenvolvimento da criança. Isso se revela não só nas obras de autores da psicologia do desenvolvimento, como Vigotski (2001), mas, a própria BNCC reserva uma larga fatia de seus vislumbres para a educação infantil voltada para essa questão. Os objetivos desse campo de experiências são todos dirigidos para a Arte e dentre os nove tópicos apresentados no documento, seis dizem respeito diretamente ao material sonoro e a educação musical.

Para bebês até (1) um ano e (6) seis meses, a BNCC apresenta como objetivos desse campo: "Explorar sons produzidos com o próprio corpo e com objetos do ambiente" e "Explorar diferentes fontes sonoras e materiais para acompanhar brincadeiras cantadas, canções, músicas e melodias" relacionados à Educação Musical, e também ao teatro e à dança, além de "Traçar marcas gráficas, em diferentes suportes, usando instrumentos riscantes e tintas" (BRASIL, BNCC, 2018, p. 48) que pode dialogar com as artes visuais, ou mesmo com a escrita, dentre outros.

Os objetivos desse campo de experiência, voltados para crianças entre (1) um ano e (7) sete meses e (3) três anos e (11) onze meses são: "Criar sons com materiais, objetos e instrumentos musicais, para acompanhar diversos ritmos de música" e "Utilizar diferentes fontes sonoras disponiveis no ambiente em brincadeiras cantadas, canções, músicas e melodias" que mais uma vez vão de encontro com a música, a 
dança e o cênico. $\bigcirc$ outro objetivo para essa faixa etária remete mais claramente às artes plásticas e aplicadas: "Utilizar materiais variados com possibilidades de manipulação (argila, massa de modelar), explorando cores, texturas, superfícies, planos, formas e volumes ao criar objetos tridimensionais" (BRASIL, BNCC, 2018, p. 48).

Para as crianças dos últimos anos da educação infantil, ou seja, entre (4) quatro anos e (5) cinco anos e ( 11 ) onze meses, esse campo de experiência busca contemplar as seguintes habilidades: "Expressar-se livremente por meio de desenho, pintura, colagem, dobradura e escultura, criando produções bidimensionais e tridimensionais", direcionado às artes plásticas, aplicadas e visuais além de "Utilizar sons produzidos por materiais, objetos e instrumentos musicais durante brincadeiras de faz de conta, encenações, criações musicais, festas" e "Reconhecer as qualidades do som (intensidade, duração, altura e timbre), utilizando-as em suas produções sonoras e ao ouvir músicas e sons" (BRASIL, BNCC, 2018 , p. 48) - perspectivas essas voltadas para o ensino musical.-

Valsiner (20 12), um autor da psicologia que tem em Vigotski, uma das fundamentações de sua obra, aponta que a formação da psiquê humana, traz em seus fundamentos sócio histórico, as concepções simbólicas culturais que contribuem no processo de desenvolvimento cognitivo, nesse sentido, devemos pensar as linguagens como estruturas simbólicas e significavas. Vigotski (2010) faz essa aproximação de significados quando relaciona o pensamento com a fala, apontando isso como o cerne do desenvolvimento infantil. A fala passa da organização concreta e objetiva para a conceitual abstrata, construida a partir da vivência cotidiana e do aprendizado formal. Esse processo se evidência em estruturas significativas e simbólicas de generalizações objetivas para crianças menores e conceituas para crianças maiores, e são fundamentais para o desenvolvimento psicológico.

A música é rica nessas estruturas simbólicas e é social em sua essência. A expressão musical nas escolas de educação infantil, é - resultado histórico de um processo que perpassa a formação da sociedade na qual a criança daquela instituição está inserida. Portanto, além de ser uma das áreas de conhecimento, ela pode revelar ao ser humano, seu próprio significado psicológico e sua estrutura potencializadora de desenvolvimento, nos mais profundos graus de conceitualização cognitiva, refinamento motor, conscientização social e organização afetiva e expressiva. 


\section{O campo de experiência Escuta, fala, pensamento e imaginação,}

tem como característica geral a estruturação da fala e da linguagem desde os âmbitos vocais até a escrita e a Arte (negrito nosso). A concepção da fala nesse item, se dá por meio do vínculo afetivo e do contexto no qual a criança está inserida. Toda a organização psicológica que essa habilidade exige vai de encontro com as formações integrais e intelectuais do ser humano, como apontado por Vigotski (2010).

Nesse campo, os objetivos almejados não fogem ao direcionamento dos outros apresentados até então. Quando se trata de bebês até (18) dezoito meses, o documento aponta elementos como "Demonstrar interesse ao ouvir a leitura de poemas e a apresentação de músicas", ou mesmo "Imitar as variações de entonação e gestos realizados pelos adultos, ao ler histórias e ao cantar" (BRASIL, BNCC, 2018 , p. 49). Mais uma vez podemos ver presente tanto o material sonoro musical como o processo de imitação nessa construção desenvolvimental.

Além do processo de imitação, no que diz respeito ao material sonoro, as orientações da BNCC indicam o estimulo a recriação de significado que o processo imitativo oferece. Os objetivos desse mesmo campo de experiência, ao lidar com crianças entre (4) quatro anos e (5) cinco anos e (11) onze meses, aponta que é necessário ao educando "Inventar brincadeiras cantadas, poemas e canções, criando rimas, aliterações e ritmos” (BRASIL, BNCC, 2018, p. 49).

A conceitualização dos elementos presentes na fala e seu desenvolvimento no ambiente escolar, transitam entre o estabelecimento de conceitos espontâneos, usuais do dia a dia, e o conhecimento formal, aprendidos por sistemas regulares de ensino, relatados por VICOTSKI (2010). Vale apontar que quando se trata de educação infantil, essas duas categorias são vivenciadas no ambiente escolar. A ludicidade, base da escolarização nessa faixa etária, revela as estruturas espontâneas necessárias nos jogos, brincadeiras, laços e inter-relações pessoais e materiais, pelo menos em tese, para um bom desenvolvimento infantil. Possivelmente essa discussão se aprofunda e revela outras facetas ao lidarmos diretamente com as múltiplas realidades estruturais e infraestruturas das escolas brasileiras, além da questão da formação de seus professores. 
$\bigcirc$ último campo de experiência traz o Espaços, tempos, quantidades, relações e transformações. $\bigcirc$ desenvolvimento sequencial temporal, a espacialidade e as abstrações quantitativas são o foco desse campo. A música, como uma arte que acontece no espaço e tempo, está profundamente relacionada com essas questões. Parizzi (2009) por exemplo, desenvolveu sua tese de doutoramento, estudando a percepção temporal da criança pequena, tendo como base o fazer musical no canto espontâneo.

Em Vigotski (2010) reportamos mais uma vez as objetividades e as abstrações do pensamento, que são bases necessárias para a criação de uma perspectiva de tempo, por parte da criança. Para a criança na primeira infância, que organiza a sua psiquê objetivamente, seja em organizações sincréticas ou complexas, a percepção temporal se difere em estrutura da organização psicológica do adulto. Quando uma criança nessa faixa etária lida com o passar do tempo, ela consegue se comunicar com um adulto a respeito disso por ter as palavras com significados pré-estabelecidos pelo próprio adulto, o que o autor soviético chama de equivalente funcional. Enquanto isso, na música além da equivalência funcional, há também uma outra forma de equivalência, no sentido de vivência, em que a regularidade temporal do adulto e da criança se equivalem nas manifestações musicais, quando por exemplo, ambos acompanham corporalmente o andamento de alguma obra, porém com estruturas psicológicas significativamente diferentes.

Além disso, a corporeidade presente na educação musical, é via para o desenvolvimento musical e também para as faculdades que esse campo de experiência almeja contemplar. Assim, nos objetivos que a BNCC traz, no que diz respeito à essa questão, podemos destacar itens como: "Vivenciar diferentes ritmos, velocidades e fluxos nas interações e brincadeiras para bebês até 18 meses (em danças, balanços, escorregadores etc.)" (BRASIL, BNCC, 2018, p. 51 ).

A percepção temporal envolve questões muito presentes na música como retardando e acelerando e essas habilidades também são evidenciadas nesse campo de experiência. Ao apontar objetivos para crianças entre um (1) um ano e (7) sete meses e (3) três anos e ( 11 ) onze meses, o documento relata: "Utilizar conceitos básicos de tempo (agora, antes, durante, depois, ontem, hoje, amanhã, lento, rápido, depressa, devagar)" (BRASIL, BNCC, 2018, p. 51 ). 
Por fim, o último objetivo que abordaremos neste texto, diz respeito a um item direcionado para as crianças entre (4) quatro anos e (5) cinco anos e (1 l) onze meses que aponta para a habilidade de "Classificar objetos e figuras de acordo com suas semelhanças e diferenças" (BRASIL, BNCC,2018, p. 51 ). Mais uma vez, é evidente a importância do processo de imitação significativa, na qual as semelhanças são organizadas psicologicamente pela criança e essas estruturas possibilitam novas abstrações.

Quando pensamos em semelhanças e diferenças em Vigotski (20 10), nos remetemos a um processo organizacional que vai da estruturação de pensamento e sua relação com a fala. $O$ desenvolvimento dessas faculdades passa de uma percepção de mundo objetiva e concreta para o subjetivo e abstrato. A psiquê da criança cria as bases de sua gênese na primeira infância e avança aos patamares conceituais de estrutura organizacional e isso, se aplica em vários âmbitos da vida do ser humano, desde a fala, ao afeto, à emoção, à arte, ao social e a própria consciência de si.

ensino e aprendizagem de música na educação infantil é um contexto complexo e ao mesmo tempo rico nas possibilidades de reflexão, diálogo e prática. Os estudos de Vigotski prenunciam a importância de o educador promover nas instituições de ensino regular, a intermediação entre a prática significativa do dia a dia e as possibilidades que essa base oferece para novos aprendizados. A educação musical, portanto, poderia e deveria, além de abordar a música tanto como uma objetivação da vida cotidiana, pragmática e significativa, abordá-la como uma forma de experiência estética que transcende as motivações ordinárias imediatas. Não se trata de ensinar a música como uma linguagem, sob uma dimensão técnica, mas experencia-la enquanto forma de expressão.

Partindo desses pressupostos, é importante ao educador musical conhecer e valorizar o conhecimento musical comum ao contexto das crianças, não só para emprega-lo como estratégia motivadora de musicalização, mas para entendê-lo como fenômeno social humano. A partir disso, devemos ampliar a bagagem musical dos educandos, criar significados novos, reestruturar a organização psicológica, não porque - conhecimento musical cotidiano deva ser negado ou considerado "inferior", mas pelo fato que a estrutura para a conceitualização 
científica nova é justamente o conceito espontâneo estabelecido ao longo da vida, ou seja, é uma construção co-dependente.

A BNCC busca contemplar todas essas questões desenvolvimentais e reconhece a importância da música na formação integral humana. Nesse sentido, as ideias de Vigotski em relação ao desenvolvimento infantil e a valorização da arte como forma de auxílio, traz para o ensino artístico-musical um espaço de transmissão de conhecimentos, mas, também um ambiente de vivência, capaz de despertar a consciência humana sobre seu lugar no espaço e tempo histórico de sua sociedade, além de promover os desenvolvimentos necessários para isso.

Por essas razões é que a educação musical deve ser um campo de aprendizagem ativa, orgânica e viva. Esse processo não deve ser, de modo algum, passivo, pois tomando como modelo a criança, ela nunca interioriza conteúdos de maneira apática, mesmo por meio da imitação. No processo de apropriação, há sempre uma reelaboração ativa dos elementos, um tipo de criação de relações que imprime no processo de aprendizado as características pessoais, individuais de personalidade e comportamento, de um sujeito inserido em um meio. Nesse sentido, o período que corresponde à educação infantil é primordial para um bom desenvolvimento humano. Cabe ao professor, enquanto mediador entre os conhecimentos espontâneos/cotidianos e os novos conhecimentos, verificar a qualidade do processo, contextualizar a aprendizagem, não fragmentar os seus conteúdos, tornar as novas organizações e os elementos compreensíveis e com sentido próprio para a criança.

Ao consideramos e refletirmos as novas perspectivas legais para o ensino de música, tomando como exemplo a BNCC, o ensino básico poderá ser um poderoso espaço que permitirá discutir, dentre outras coisas, as características das músicas que os alunos ouvem e gostam e porque elas ouvem e gostam deste repertório; por quem, para quem e por que motivo elas são elaboradas; como elas são elaboradas e quando são ouvidas. De forma global é bom avaliar que funções as músicas exercem na vida das pessoas e na vida social em geral.

Tais questões certamente ampliarão as motivações para as práticas musicais diferenciadas, além das possibilidades de escuta e de apreciação musical dos diferentes tipos de música. Esse seria um enfoque sociológico e também psicológico da música, pois, antes de centrarmos nossa atenção em características estruturais e estético-musicais, as

\section{6}

REV. TULHA, RIBEIRÃO PRETO, v. 6, n. 2, pp. 64-89, jul.-dez. 2020 
características sócio-históricas, simbólicas e afetivas, tomam um espaço significativo nesse aprendizado.

Por fim, o limite entre a música como prática sociocultural ou como Arte é muito tênue, pois, para cada indivíduo, a música possui significados particulares e universais específicos, os quais não podem ser categorizados nem mesmo mensurados objetivamente. Essa bagagem cotidiana de conhecimento musical é a base para a construção significativa, para um processo de Catarse que vai direto ao encontro da estrutura da psiquê humana em seus diversos âmbitos: cognitivo, afetivo, motor, social, cultural, simbólico e emocional, dentre outros.

Resta mencionar, que embora a BNCC não tenha referendado a teoria desenvolvimental de Vigotski como fundamentação de suas argumentações, de certa forma ela evoca parte dos relatos desse autor.

\section{Referências}

BRASIL. Ministério da Educação. Base Nacional Comum Curricular. Brasilia, DF: MEC, 2018. Acesso em Ol de maio de 2020. Disponivel: http://basenacionalcomum.mec.gov.br/abase/\#infantil

BRASIL, Emenda Constitucional n 59/2009. Acesso em 19 de dezembro de 2020. Disponivel: http://legislacao.planalto.gov.br/legisla/ legislacao.nsf/Niw_Identificacao/emc\%2059-2009?OpenDocument

LIMA, Sonia R. A (org). Ensino Musical Brasileiro: Múltiplos olhares. $1^{1}$ ed. São Paulo. Musa Editora. 2020.

PARIZZI, Maria Betânia. O desenvolvimento da percepção do tempo em crianças de dois a seis anos: um estudo a partir do canto espontâneo. Tese de Doutorado, Faculdade de Medicina, Universidade Federal de Minas Gerais, Belo Horizonte, 2009.

PRESTES, Zoia. R. Quando não é quase a mesma coisa: traduções de Lev Semionovitch Vigotski no Brasil Repercussões no campo educacional. Tese de Doutorado Faculdade de Educação, UNB, Brasilia. 2010.

VALSINER, J. Mundos da Mente, Mundos da Vida. 2 ed. Porto Alegre: Editora Artmed 2012. 
VICOTSKI, Lev Semenovich. Psicologia da Arte. 2 ed. SP: Martins Fontes, 2001.

VICOTSKI, Lev Semenovich. Aprendizagem e Desenvolvimento Intelectual. In: Psicologia e Pedagogia: Bases Psicológicas da Aprendizagem e do Desenvolvimento - Luria, Leontiev, Vygotski e Outros. São Paulo: Centauro, 2005, pp. $1-17$.

VICOTSKI, L. A construção do pensamento e da linguagem. São Paulo: Editora Martins Fontes, 2009.

\section{Sobre os autores}

Cícero Rodarte Mião - Doutorando em Música com ênfase em Educação Musical pela Universidade Estadual Paulista Júlio de Mesquita Filho, Mestre pelo Programa de Mestrado em Psicologia da Universidade Federal de São João del-Rei, na área de Psicologia Social e Socioeducativa, graduado em Educação Musical - Licenciatura, pela Universidade Federal de São João Del-Rei. Idealizador e atuante no programa universitário "Música Viva" que atendeu crianças em situação de vulnerabilidade social em São João del-Rei-MC entre 2011 e 2017, projeto esse contemplado com certificação de Honra ao Mérito por Extensão na Universidade Federal de São João del-Rei. Idealizador, articulador e docente no processo de implantação de oficinas de musicalização nos berçários da na Rede Municipal de Educação Infantil de São Sebastião do Paraíso-MC. Docente no curso de Pedagogia da Libertas Faculdades Integradas em São Sebastião do Paraíso-MC.

Sonia Regina Albano de Lima - Doutorado em Comunicação e Semiótica- Artes (PUC-SP); pós-doutorado em Interdisciplinaridade e Educação pelo Grupo de Estudos e Pesquisa em Interdisciplinaridade da PUC-SP (CEPI-PUC- SP ); pós-doutorado em música realizado no Programa de Pós-Graduação em Música do IA-UNESP, pós-graduação lato sensu em práticas instrumentais e música de câmara (FMCG); especialização em interpretação musical e música de câmara com o Prof. Walter Bianchi ( FMCG); bacharelado em instrumento - piano (FMCG); bacharelado em direito (USP); licenciatura curta em educação musical e habilitação para o ensino de piano (Instituto Musical de São Paulo). Estudou piano e música de câmara regularmente com os professores Martin Braunwieser, Sonia Muniz, Roberto Sabbag e Walter Bianchi. 
Participou de cursos de extensão com intérpretes nacionais e internacionais, entre eles destacam-se Bruno Seidholfer, Camargo Guarnieri, Rosalyn Tureck, Sérgio Magnani e Homero Magalhães. Foi professora de piano da Escola Municipal de Música. Na FMCG foi professora de música de câmara e piano; vice-diretora; diretora executiva; coordenadora pedagógica dos cursos de graduação (canto, instrumento, composição e regência) e pós-graduação lato sensu em educação musical e música. Foi professora pesquisadora da UNIABC para a implantação do Mestrado Profissional; bolsista coordenadora de pesquisa da FUNADESP. É professora do Programa de Mestrado e Doutorado do IA-UNESP. Foi diretora e coordenadora artística da Escola de Música de São Paulo. É pesquisadora junto ao Grupo de Estudos e Pesquisas em Interdisciplinaridade do Programa de Pós-Graduação em Educação (Currículo) da PUC-SP (CEPI-PUC-SP) e $2^{a}$ líder de pesquisa do Grupo de Pesquisa em Educação Musical do IA-UNESP (CEPEM). É colaboradora junto ao Projeto Pensar e Fazer Arte da PUC-SP sob a organização do Prof. Dr. Claudio Picollo. Autora e organizadora de livros, coletâneas e textos de revistas científicas voltadas para a interdisciplinaridade, performance e educação musical. Foi Presidente da Associação Nacional de Pesquisa e Pós-Graduação em Música de 2015 a 2019.

Recebido em 26/10/2020

Aprovado em 24/12/2020 